\title{
Developing a Public Online Learning Environment for Crisis Awareness, Preparation, and Response
}

Liz Bacon, Faculty of Architecture, Computing and Humanities, University of Greenwich, London, UK

Lachlan M MacKinnon, Department of Computing and Information Systems, University of Greenwich, Old Royal Naval College, London, UK

Avgoustinos Flippoupolitis, Department of Computing and Information Systems, University of Greenwich, London, UK

David Kananda, University of Greenwich, London, UK

\begin{abstract}
This article describes the design and development of an online immersive learning environment focused on enhancing the general public's awareness of, and preparation for, crisis situations. This research has sought to answer the question "Is it possible to develop a timeline based immersive and engaging training environment for mass self-study education in crisis preparedness?" The system developed is based on the Pandora ${ }^{+}$training environment and integrates original collaborative European research work carried out on eLearning and Crisis Management over the last ten years. The research reported here not only describes the design of the Pandora+ training environment but also the outputs from a pilot trial in Lisbon run by the POP-ALERT EU FP7 project. Where appropriate, the results were also compared to those from a large EU survey on crisis preparedness and attitudes, also undertaken within POP-ALERT. The results of this article have resulted in an original and innovative system that has significant potential to transform the education of the public in disaster preparedness.
\end{abstract}

\section{KEYWORDS}

Crisis Preparedness, MOOC, Online Learning, Public Self-Study

\section{INTRODUCTION}

For the past ten years the lead authors have been involved in a research agenda encompassing the provision of, and support for, training for all stakeholders involved in crisis management. Predominantly, our wish is to make well-formed and easily accessible training materials available at relatively low cost, to improve the quality of public and professional response in crisis situations. To enable this work, the authors have been involved in a number of publicly funded research projects related to this research agenda, and this paper brings together outputs from three of those projects in the design and development of an online vehicle and training materials to help develop population awareness. Chronologically, the three projects are, the Pandora project, the dCCDFLITE project, both of which are described later in the paper, and finally the POP-ALERT project, which is the main focus of this work and is about to complete. POP-ALERT is an EU FP7 project involving eleven partners from seven countries across Europe. Its focus is the preparation of societies and populations to cope with crises and disasters in a rapid, effective and efficient way. The POP-ALERT team has undertaken 
a thorough review of the literature on approaches, population behaviours (including willingness to prepare), first reaction strategies, awareness of risk etc. The focus of this work is not only on local populations but also vulnerable groups, such as tourists, expatriates, the elderly and refugees, and the effectiveness of the use of messages, audible alarms, pictograms etc. on these population groups. The POP-ALERT project has generated a framework encompassing a variety of tools and techniques to enhance population awareness, realised as an online dashboard, and concluded with local and distributed field studies to test the effectiveness of this framework.

To support the field studies in POP-ALERT, the authors utilised a bespoke version of Pandora ${ }^{+}$ ( ${ }^{1}$ Bacon et al., 2015), which is the enhanced development of a product called Pandora (Bacon et al., 2012; MacKinnon et al., 2013), one of the key outputs from an EU FP7 project, which ran between Jan 2010 and March 2012. Pandora ${ }^{+}$is an immersive, rich multimedia, training environment initially designed to provide realistic training for strategic level crisis managers, who, in the event of a crisis, need to work together to come up with a plan of action and take decisions as the crisis situation unfolds. The Pandora ${ }^{+}$system is not however specific to crisis management, it is a sophisticated environment into which a wide variety of scenarios from any domain can be uploaded and executed. It has an event network approach, which presents trainees with a series of events that occur within a specified timeline and requires them to make decisions about what to do at specific points on that timeline. The timeline then has the capacity to branch the scenario depending on the answer provided by the trainee(s). An example of a different domain could be a trainee's analysis of the rise and fall of the stock market in relation to specific events, and making decisions about stocks and shares to purchase / sell etc.

The Pandora ${ }^{+}$environment was utilised in a field study in POP-ALERT that was used to train members of the general public in Lisbon in February 2016. The scenario focused on an earthquake as an example of a natural disaster. One purpose of the trial was to test the use of Pandora ${ }^{+}$and the POP-ALERT dashboard on a small sample of the population as a pilot, before running it as a self-study massive open online course (MOOC) ( ${ }^{2}$ Bacon et al., 2015), with members of the general public able to register and follow the training course at a time suitable to them and for a duration of their choosing.

In making the shift from training professional crisis managers, to a MOOC used by the public, changes to the Pandora ${ }^{+}$environment were required, and this included taking on board the behaviours and approaches to training by the general population, when engaged with self-study. These changes came from lessons learned from the recent delivery of a MOOC on Entrepreneurship and Innovation, in which some of the authors were involved, as part of an Erasmus, Life-long learning programme project, called dCCDFLITE - distributed Concurrent Design Framework for eLearning in IT Entrepreneurship (FLITE for short), which ran from 1st Oct 2010 to 30th September 2015 ( ${ }^{2}$ Bacon et al., 2015).

Combining the outputs of these three projects provides a unique and innovative system that aims to answer the research question "is it possible to develop a timeline based immersive and engaging training environment for mass self-study education in crisis preparedness?".

The rest of this paper is structured as follows: it first of all discusses some of the key issues in attitudes and training of the general population in crisis response and the need to take into account behaviours, attitudes, willingness to prepare etc. It then discusses the factors to take into account from the educational perspective and the research around online education and MOOCs. Finally, it focuses on the design and development of a distributed version of Pandora ${ }^{+}$required to train the general population in crisis preparedness, reports on the results from the Lisbon pilot, and then draws some conclusions and outlines future work. 


\section{POPULATION PREPAREDNESS: ATTITUDES AND BEHAVIOURS}

When a crisis occurs, and a population is alerted, people go through several stages in their cognitive thought processes which are reasonably consistent across the population regardless of whether there is an immediate threat or not. The sequence of thought is typically as follows: receive, believe, personalise, respond and confirm (Paton 2006; Mileti \& Peek 2000; Perry et al. 1982) and these can occur quickly for an immediate threat or over a longer period of time if a crisis situation is unfolding. In terms of personalisation, people ask themselves what it means for them, and that is the key question people will seek answers to during a crisis in order to assess their personal risk going forward. Research has shown that the greater the relevance to oneself, the greater the perception of risk (Dow \& Cutter, 1998; 2000).

There are however many factors which influence a person's decision whether or not to prepare for a possible crisis, and their behaviour during a crisis. Key findings are summarised below:

- The manner in which information on a disaster or crisis is presented is key to people's reaction, for example how certain information is, severity, immediacy, proximity, nature of the event, or certainty of a potential event (Seydlitz et al., 1994). It seems that people tend to overestimate risk for rare events and underestimate risk for seemingly frequent events. People's beliefs about a hazard can be a mix of factual knowledge, misinformation, myths, hypothesis, beliefs about human beings, trust in authorities etc.

- Women are more likely to prepare because they have a higher perception of risk (Fothergill, 1996 cited in Paton, 2006), however, this is affected by cultural issues, decision-making cultures of the family, etc. Men are more likely to tune in to TV and radio, whereas women are more likely to use social networks and call people (Bagrow et al., 2011).

- Most people have a significant expectation that local authorities and central Government will prepare for, detect and manage disasters, and their recovery. They expect clear communication, and for the authorities to look after them in the event of a disaster.

- Confident people, or people with high self-efficacy, tend to believe that a threat will not affect them, and they tend to think positively about a threat. They are also less likely to prepare for disasters. Their belief in their own coping strategies may mitigate their sense of risk to daily routine and property.

- Whether someone is resident in an area where they perceive that a disaster might occur.

- People who have more experiences of disasters are inclined to have an optimistic view about their capacity to survive but are also more likely to adapt their behaviour.

- The cost and inconvenience of preparation is a factor in peoples' decision to prepare.

There are however many vulnerable groups at a time of disaster, and it has been shown that the less control a disadvantaged person has, the less likely they are to prepare (Legates \& Bidel, 1999). Vulnerable / disadvantaged groups can be summarised as follows:

- Transient populations such as tourists, travellers, migrant workers, clandestine communities and overseas students. In general, they are considered at a disadvantage during disasters (Quarantelli, 1994) as they are not integrated into local communities. This disadvantage may be why transient people are amongst the earliest to evacuate when disaster becomes a prospect but are less likely to be prepared or to have taken precautionary action. They are also the least likely to seek help from authorities (Lindell \& Perry, 2004).

- A list of vulnerable groups from the Vulnerable Populations Outreach Model based on Englishspeaking nations (Klaiman et al., 2010) was developed to identify people at risk during disasters. These include: non-English speakers, visually impaired, hearing impaired, isolation due to economic circumstances, isolation due to medical circumstances, low levels of literacy, homeless, 
prisoners, below the poverty level, people who depend on service animals, children, older and frail adults and unemployed people.

- Minority groups (gender, religion, ethnic, disability, sexuality, income) are often more vulnerable for a variety of reasons e.g. differences in terms of resources, inappropriateness of generic training programmes, and they have been found to be less likely to evacuate (Perry et al., 1982), as they exhibit higher levels of scepticism about warnings. Other reasons why minority communities are more vulnerable include social, economic, culture and language barriers, lower perceived personal risk, distrust of messages, lack of preparation and protective action, and reliance on informal sources of information.

- Disaster spectators and volunteers who travel to a disaster site for curiosity, adventure, to help, to witness a continuing disaster, etc. These include news media, people wanting to witness an on-going crisis e.g. storm chasers, people wanting to help but not knowing how, etc. People can put themselves in vulnerable situations intentionally and unintentionally, and authorities need mechanisms to deal with the full range of these people.

As part of the POP-ALERT project a survey was conducted across Europe of citizen's experiences of disasters, their perception of threat and risk, their expectations of authorities and their attitudes to preparation. The survey was answered by 1612 participants and was issued in 6 languages, the breakdown being: 610 English-language participants, 483 French-language participants, 62 Dutchlanguage participants, 88 Greek-language participants, 145 German-language participants, and 224 Portuguese-language participants. The full survey results are reported elsewhere (Filippoupolitis et al., 2015), however given the focus here is on training the population in preparedness, two key questions were asked about people's willingness to prepare and the results were as follows in Tables 1 and 2:

For those who did not intend to prepare or intended to prepare (first two answers) they were asked a follow up question. Note that they could tick multiple answers and the average respondent ticked 1.66 answers:

Table 1. Initial Survey Question Results

\begin{tabular}{|l|l|}
\hline Which statement best represents your preparedness for a disaster? \\
\hline I do not intend to prepare & $15.80 \%$ \\
\hline I intend to prepare & $42.96 \%$ \\
\hline I just started preparing & $19.88 \%$ \\
\hline I am prepared & $21.36 \%$ \\
\hline
\end{tabular}

Table 2. Follow-up Survey Question Results

\begin{tabular}{|l|c|}
\hline Why have you not prepared? & $35.94 \%$ \\
\hline I don't know what I should do & $16.80 \%$ \\
\hline I didn't have time & $6.82 \%$ \\
\hline It costs too much & $9.03 \%$ \\
\hline I don't think it is important & $11.37 \%$ \\
\hline I don't think it is possible & $13.90 \%$ \\
\hline Emergency services will help me & $6.13 \%$ \\
\hline Other & \\
\hline
\end{tabular}


So, the good news is that if we assume that the $15.85 \%$ of this group that say that they don't think it is important or it costs too much are unwilling to prepare, we can also reasonably assume that the other responses are open to negotiation. This may provide a means of addressing at least some of the $15.8 \%$ of the population who do not intend to prepare. However, pragmatically we can target the $42.96 \%$ of the population that may be willing to prepare but are clearly unsure how or are concerned over time for example, and also the $19.88 \%$ that have only just started preparing, which provides a significant proportion of the population that are potentially open to the provision of training.

The fact that only $21.36 \%$ of the respondents are actually prepared for a crisis situation gives a clear indication of the scale of the problem, especially when you consider that the respondents to the survey were inevitably those who had a greater level of interest in, or awareness of, the issues. Whilst we might seek to make inroads into the group who do not intend to prepare through public information programmes or targeted approaches, the reality is that these are only likely to become effective when the majority of the population is prepared, so focusing on those who are willing to prepare is likely to be more beneficial in the long term.

It is clear from the survey that information on how to prepare is not perceived to be easily available to the population or is not seen as a priority. However, regardless of planning and preparation, respondents cited many reasons why they may delay evacuation, including seeking further clarification from official sources, caring for relatives, evacuating pets, and gathering personal belongings. So, the design of any preparation training needs to take into account issues that might cause such delays and provide information and support in resolving these issues. However, it was noted in the German survey that the highest percentage of participants that would delay evacuation are among those who do not intend to prepare, which clearly compounds the problem, and provides information for emergency services rather than the design of preparation training.

We can also draw on a higher level of willingness to prepare when travelling abroad, or on public transport, expressed in the survey, as evidence that properly targeted and designed awareness and preparation training has the potential to be effective. In fact, the survey suggests that making such training readily and easily available, sanctioned and supported by local authority and emergency services, could have a significant impact on public awareness and levels of preparation.

\section{ONLINE EDUCATION AND MOOCS}

In Europe, the literature on the benefits of training the public and the benefits of training first responders is sparse and suggests that learning may not result in more protective action (Leonard et al., 2008). For example, half of the people who had attended training in one study said they knew how they would be informed if there was a disaster, however a third did not recognise the alarm signal after the training had been given. Lalo (2000) observed that there is not necessarily a direct link between people's actual behaviour and what they learned, and of course learning fades over time. He concludes that efforts designed to promote "social unity" are significant in shaping responses before any disaster. This predicates regular and easy access to training for reinforcement of learning.

It is however clear from our research that the vast majority of the population are willing to prepare but a significant proportion do not know how. There are many websites providing advice on disaster preparation and associated kits for both humans and pets, however from the respondents' answers to our survey questions, it would appear most are not aware of them, as they are unclear how to prepare and these would have been a useful resource. Interestingly, there has been at least one attempt to offer disaster preparation in the form of a MOOC, which has run on the Coursera MOOC platform several times, however MOOCs in general tend to have very poor success rates so it could be argued that they may not be the best approach. However, they do remain attractive, as they have the ability to engage a large audience and traditional approaches may not be sufficient given the scale of the training required for the populations identified, or the ability of those populations to locate training. 
From our experience, MOOCs do have their challenges, the pedagogy is important and many tutors approach online education in the same way as traditional teaching, with the end result being a poorer version of a classroom-based approach put online. In a MOOC, the role of a teacher has to change to become more of a facilitator than an instructor as, given the number of students involved, personalised tuition by an instructor is impossible. However, personalisation of the learning environment is of course possible, and more so than in a classroom-based approach. In recent times there has been a move more towards cMOOCs, which are based on a constructivist, student-centric approach to learning, which supports student independent learning facilitated by an instructor. Irrespective of the approach, as noted above, MOOCs suffer from high dropout rates and there are a number of reasons for this, such as a student's ability to cope with less support from the instructor in a less structured environment which requires them to become a more independent learner, manage their own workloads and time etc. Research suggests that if a student is to be successful then it is crucial that they feel part of a learning community (Ellis 2001; Bernard 2000). However, many MOOC learners can struggle with a MOOC online community feeling overwhelmed by the volume of material, choice of learning materials available, the complexity of the environments, the tools used, the number of parallel conversations taking place, networks that form and disband as time passes, etc. (Kop et al., 2011). Whilst the facilities available on different MOOC platforms differ, they all have a typical common core, for example, a place where learner materials are located, links to reading materials, videos to watch, discussion fora for debates, quizzes etc. However, by comparison, players engaged in immersive online gaming environments, which are also open to massive numbers, MMORPGs (Massive Multi-Player Online Role-Playing Games), achieve far higher levels of engagement and return. In general, whilst there may be short-lived immersive components within a MOOC, they are generally not fully immersive, engaging experiences. So, our approach here is to combine the best of both worlds, i.e. to provide an engaging and fully immersive, rich multimedia, training environment as a MOOC platform.

Whilst the experience will be designed to be engaging, our research also raised the issue of how we measure success within a MOOC. The traditional measure is to gauge success by the teacher's expectations, which are traditionally that all students will complete the course to the end and submit some final assessment as proof of completion. However, when we asked the students in our MOOC their intentions at the start of the course, close to 50\% made it clear they had no intention of completing the course (and those were the ones sufficiently engaged to answer the questionnaire). They made a decision at the start what they expected to get from it, e.g. many were looking for some specific piece of learning and just planned to dip in get the snippet of learning they wanted. So, measuring success by completion is not appropriate in MOOCs as one could clearly argue that if the student got from it what they wanted, then that should be counted as a success.

So, in order to provide mass online disaster preparation education for the general public, a decision was taken to develop the Pandora ${ }^{+}$environment as a distributed, online, self-study, immersive environment that could be run as a MOOC platform. The following section provides details of the design and development of the distributed online version of Pandora ${ }^{+}$.

\section{PANDORA+ DESIGN AND DEVELOPMENT}

This section focuses on the changes that have been required to the Pandora ${ }^{+}$training environment to be able to deliver training to the general public in the form of a MOOC.

A key focus of the design of the Pandora ${ }^{+}$environment is the management of trainee stress, as research has shown a clear link between stress and cognition (Sales et al., 1996). Stress reduces a person's psychological capacity. It can reduce their ability to undertake protective behaviours including information seeking and processing that information (Vihalemm et al., 2012). In short, a person's decision-making abilities are affected by their level of stress, with the potential for someone to devote insufficient time to considering alternative solutions and also to consider them in a disorganised 
manner, and to make decisions before considering all the potential information, etc. For this reason, the Pandora ${ }^{+}$environment was designed with a number of controls to support the trainer in managing the stress of each trainee in order to create as realistic a crisis environment as possible.

The type of controls the trainer has include:

- The ability to dynamically change a scenario during a training session depending on how each trainee is responding

- The ability to speed up or slow down the execution of a scenario

- The ability to add new events to the scenario to create more pressure on the trainees, e.g. inform them that a lorry has just crashed in a local tunnel and its cargo has now polluted the water supply of the local town

- The ability to role play a character in the scenario to allow the trainer to explore the thinking of trainee group and thus allow a wider range of outcomes from the training event.

The Pandora ${ }^{+}$training environment has some automated features to help manage the stress of the trainees, including an initial questionnaire to assess behavioural traits such as self-efficacy, personality traits, stress and anxiety, leadership style etc., and other measures such as biometric inputs and selfreporting. As a result, the system can automatically add events from its rule-based engine to try and increase or decrease the level of stress of one or more trainees. However, this feature of the system was not being used in the pilot trials to begin with due to the practicality of capturing biometric data, and also the nature of scenario development for individuals with different experience levels. Prior to the pilot, the system had only been tested on crisis management professionals, not the general public, so it was felt that more trials were required, post pilot, before attempting to generate the stress of a realistic crisis scenario in the general public, however this is an important area of research that will be required in future to deliver more realistic crisis preparation training.

Both the original Pandora and current Pandora ${ }^{+}$systems were initially designed to be used only in an environment with a trainer present. They were both therefore developed to run over a local area network with the client installed on the trainee computers and the server installed on the trainer computer (see Figure 1). However, this is not practical for use with the general public and so a number of changes to the Pandora ${ }^{+}$training environment, to enable it to be used as a MOOC platform, were required. In order to retain the rich multimedia, immersive nature of the environment, it was still required to be focused around a scenario incorporating a wide range of multimedia elements, with a sequence of time-driven events demanding regular decisions / input from the trainees, but it could no longer be driven by the presence of a human trainer. The system had to be offered as a web service so that the trainee environment could be run in a standard web browser (see Figure 2), rather than requiring any specialist software to be installed on the trainee machine. Additionally, to reduce requirements on the users to learn an unfamiliar interface in order to use the system, the interface was designed to be similar to the interface design of Microsoft ${ }^{\circledR}$ Office, being possibly the most familiar interface worldwide. Since it was not possible to predict what devices users would wish to use for the training, a responsive design approach was adopted to enable the interface to be viewed on mobile devices if necessary but noting that the volume of information to view on a mobile at any one time would be particularly challenging. At the pilot, laptop machines were used for all participants.

Another major change to the design was to parameterise the language used for all the interface and help information. This was necessary to enhance engagement with the general public across Europe. Obviously, the actual scenario information uploaded, including the multimedia assets, e.g. a news video of a disaster report, was subtitled for the local language of delivery.

Taking on board the lessons learned from the MOOC, the length of the training scenario is significant. Many more people will find time for five minutes of training than thirty minutes of training, however many may wish to do more than five minutes and so bite-sized chunks of training are important to offer to the public, divided up by topics of key interest to them so they can choose 
Figure 1. Trainer Interface: Showing Scenario Text Highlighted and Associated Timelines

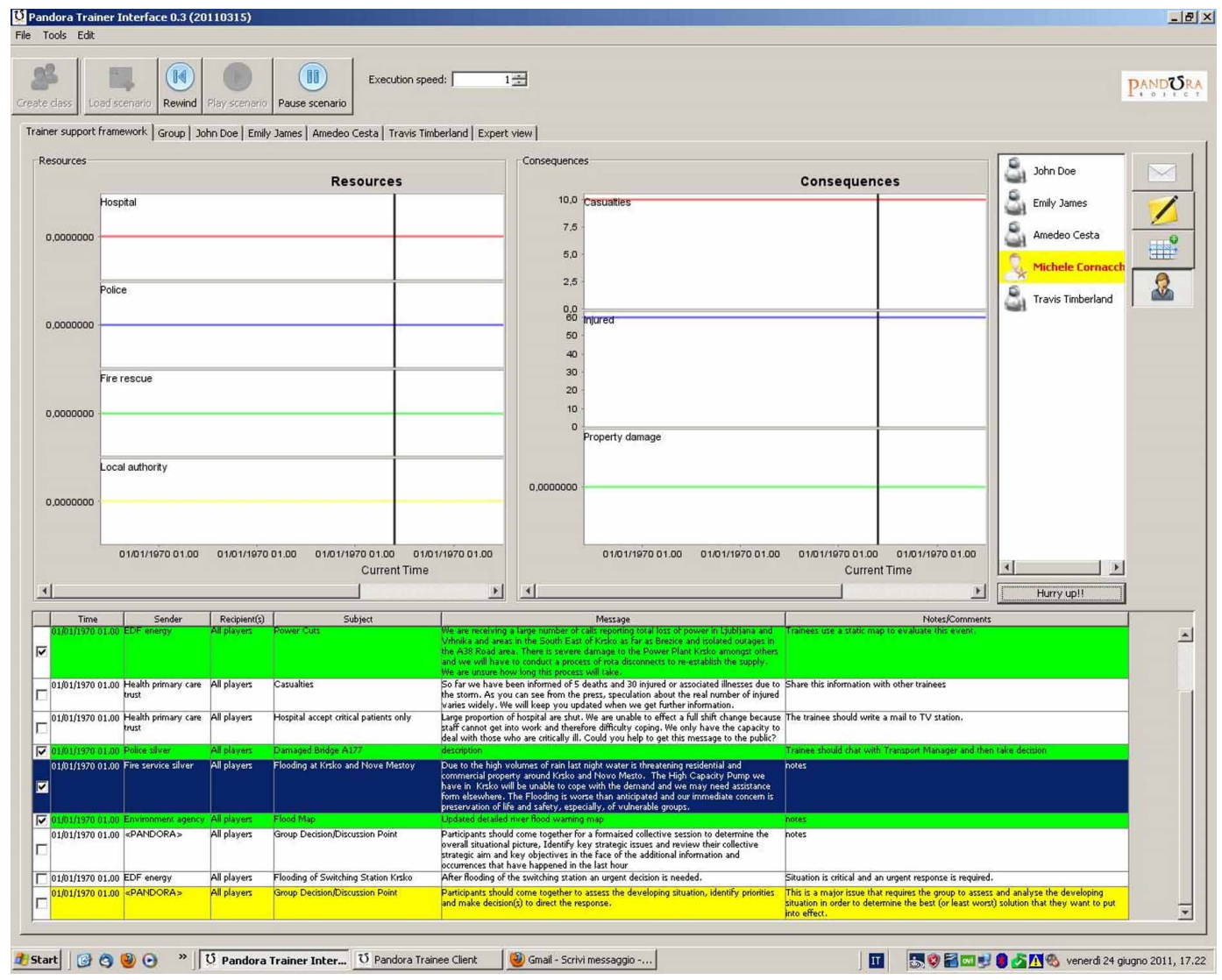

the order in which they engage. However, for the pilot, with a captive audience, a 35-minute scenario was utilised.

One of the key features of the Pandora ${ }^{+}$system of note is the recording feature, which logs all communication and decisions made by a group of trainees for use in debriefing sessions with the trainer after a training event, either as a group or an individual. Whilst there is no trainer in this distributed pilot version, because the public were asked to work through the scenario in the same room but at their own pace the recording tool is still a valuable feature, in that it gathered data on decisions taken by the public. When used for the large trials with the public, it will provide rich information about how people may perform in the event of a crisis. This data will be gathered and analysed on an ongoing basis to enhance the training materials. Combined with the demographic data captured when users register to use the system, this will also provide a rich source of data that can be analysed not only to improve the quality of the training materials, but also to determine user appetite for training, preferences for type and nature of information and support for preparation, and levels of knowledge and preparation. Potentially, this could be a rich source of data for future crisis preparation initiatives and may offer a vehicle for trials of such initiatives.

\section{RESULTS FROM LISBON TRIAL}

In this section we present the results of a real-world trial we conducted in Lisbon, Portugal in Feb 2016. The goal of the trial was to assess whether the POP-ALERT dashboard could be beneficial to 
Figure 2. Trainee Interface: Modeled on MS $®$ Office Look and Feel

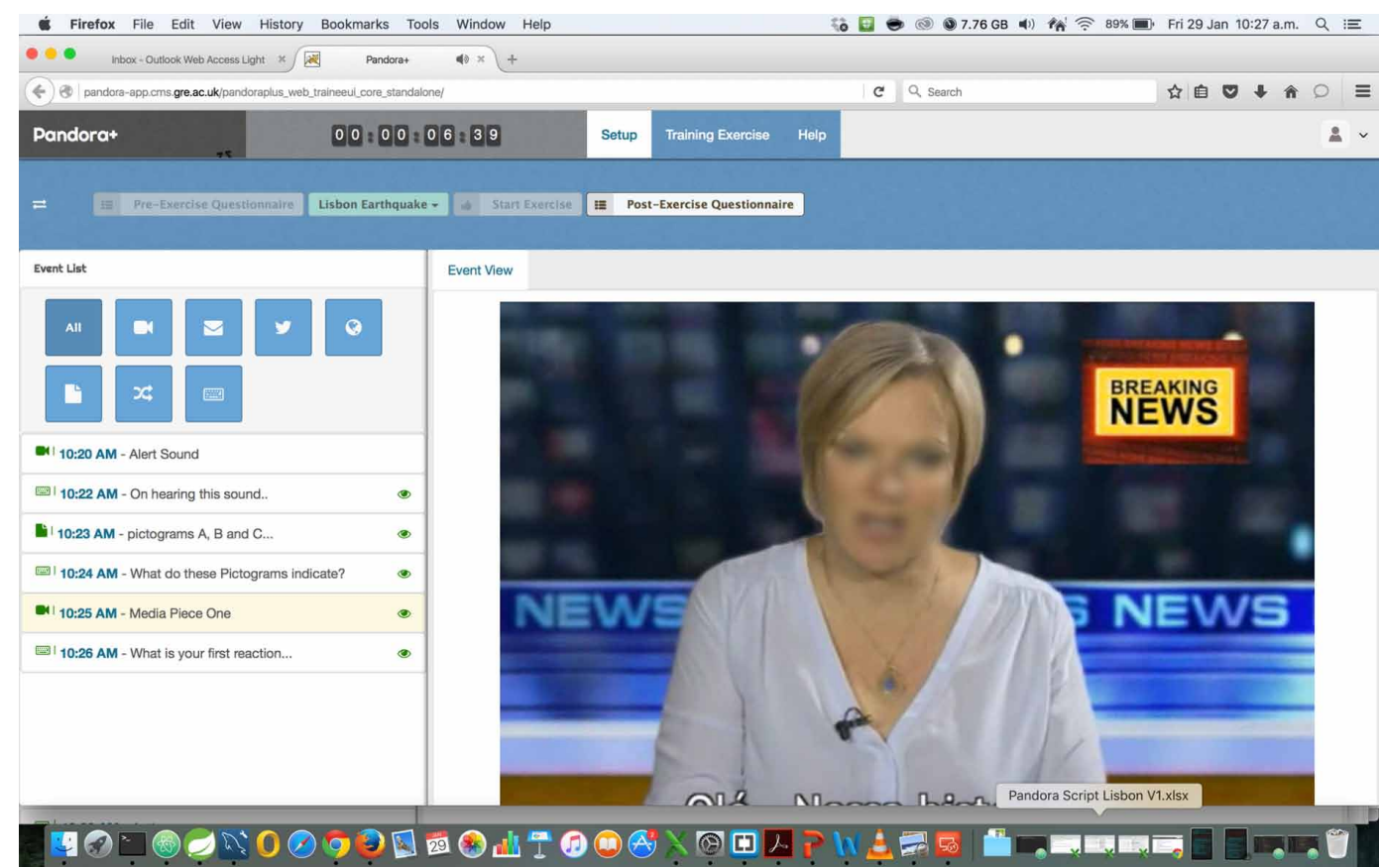

the way populations respond to disasters. The POP-ALERT dashboard is one of the key outputs of the project and is designed to provide tools for the general population to prepare for various disasters and crisis, receive alerts, understand their local alerting system, receive notifications from social media, etc. A second dimension to the dashboard is to provide tools for public authorities to help them work better with the general population, including tips on how to create an informative website, how to use social media for alerting and preparedness, how to plan an awareness raising campaign, how to train the general population, etc. However, the focus of the pilot was to test its use with the general population.

To achieve that, we used the Pandora ${ }^{+}$system to model an earthquake scenario taking place in Lisbon. The total number of participants was 65 and they were divided in two groups: a control group composed of 29 participants and an experimental group involving 36 participants. Both groups used the Pandora ${ }^{+}$training environment and were asked to provide responses to questions, for example about actions they would take as the disaster scenario unfolded. The difference between the two groups was their order of exposure to the dashboard. More specifically, the control group was asked to first use Pandora ${ }^{+}$and go through the emergency scenario without having used, or known about, the existence of the POP-ALERT dashboard. On the other hand, the experimental group first went through a training session that aimed to introduce them to the features and the functionalities of the POP-ALERT dashboard (Figure 3). After this, the participants used the Pandora ${ }^{+}$system to work through the earthquake scenario and answer the questions illustrated in the following tables. Before proceeding with the analysis of the trial data, it is important to note that the recording mechanism described above captured the responses of the users while also providing them with an immersive experience involving an evolving disaster situation related to an earthquake. This experience included the use of streaming video to announce the emergency to the public, display of safety pictograms that the user had to identify and a wide range of questions on emergency awareness, preparedness and actions they would take in response to the unfolding events. 
Figure 3. The POP-ALERT Dashboard Home Page

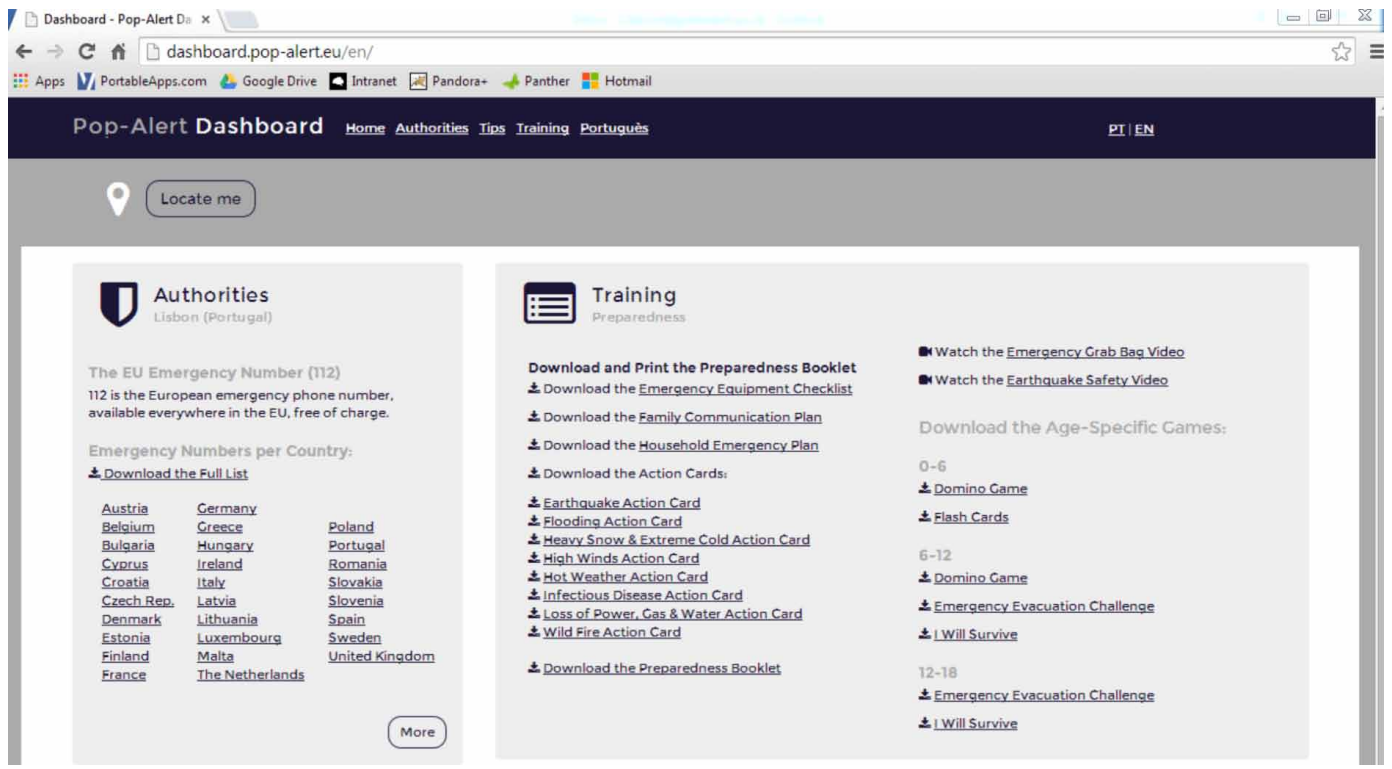

Table 3. Responses to question on "What was your first reaction to seeing the news regarding the earthquake?"

\begin{tabular}{|c|c|c|}
\hline \multicolumn{3}{|c|}{ First reaction to seeing the news } \\
\hline & Control & Experimental \\
\hline Keep safe & $10.34 \%$ & $13.89 \%$ \\
\hline Concerned & $13.79 \%$ & $2.78 \%$ \\
\hline Check on people nearby & $10.34 \%$ & $2.78 \%$ \\
\hline Prepare ER kit & $0.00 \%$ & $8.33 \%$ \\
\hline Shocked & $3.45 \%$ & $5.56 \%$ \\
\hline Alarmed & $3.45 \%$ & $2.78 \%$ \\
\hline Listen to TV/radio & $0.00 \%$ & $5.56 \%$ \\
\hline Buy food & $0.00 \%$ & $2.78 \%$ \\
\hline Keep calm & $3.45 \%$ & $0.00 \%$ \\
\hline Offer help & $0.00 \%$ & $2.78 \%$ \\
\hline
\end{tabular}

Some of the answers to the questions from both groups are discussed below. As we can observe from Table 3, the experimental group has given more detailed answers with respect to their first reaction. In contrast to $13.79 \%$ of the control group who stated that seeing the news would make them concerned, only $2.78 \%$ of the experimental group members shared this view. Although their most popular answer was that they would keep safe, which is lacking detail, the next most popular answer was that they would prepare an ER (emergency response) kit. The latter, along with answers such as listening to the radio and buying food, illustrate that using the dashboard has helped the participants having a more appropriate first reaction to the news of an evolving disaster. 
Table 4. Responses to question on "If you have a pet: What would you do with them during the earthquake?"

\begin{tabular}{|c|c|c|}
\hline \multicolumn{2}{|c|}{ If you have a pet: What would you do with them during the earthquake? } \\
\hline & Control & Experimental \\
\hline Keep with me & $51.72 \%$ & $19.44 \%$ \\
\hline Leave in safe place & $10.34 \%$ & $33.33 \%$ \\
\hline Put on a leash & $0.00 \%$ & $19.44 \%$ \\
\hline Calm them down & $3.45 \%$ & $5.56 \%$ \\
\hline Nothing & $0.00 \%$ & $5.56 \%$ \\
\hline Set free & $6.90 \%$ & $0.00 \%$ \\
\hline Abandon & $0.00 \%$ & $2.78 \%$ \\
\hline
\end{tabular}

Table 5. Responses to question on "If you have a pet: What would you do with them after the earthquake?"

\begin{tabular}{|c|c|c|}
\hline \multicolumn{2}{|c|}{ If you have a pet: What would you do with them after the earthquake? } \\
\hline & Control & Experimental \\
\hline Check on them & $10.34 \%$ & $5.56 \%$ \\
\hline Take with me & $10.34 \%$ & $5.56 \%$ \\
\hline Calm them down & $3.45 \%$ & $5.56 \%$ \\
\hline Put on a leash & $0.00 \%$ & $2.78 \%$ \\
\hline Leave in safe place & $10.34 \%$ & $33.33 \%$ \\
\hline
\end{tabular}

The beneficial effect of having been introduced to the dashboard is depicted in Table 4. As we can confirm, the experimental group's most popular answer was that they would leave their pets to a safe place, an action that coincides the suggested one found in the dashboard. On the contrary, the vast majority of the control group stated that they would keep their pets with them, which is not the recommended action. Table 5 also illustrates the benefits of the dashboard, captured via the interactive interface of Pandora ${ }^{+}$. More specifically, the majority of the dashboard users again stated they would leave their pets in a safe place and only $5.56 \%$ that they would take them with them.

There is little difference between the results in Table 6. Overall, both groups have given similar answers regarding their reaction when indoors. The same stands for the case of outdoors. These results indicate that depriving the user of the resources of the dashboard did not have an effect on

Table 6. Responses to question on "If you are directly affected by the earthquake: What actions would you take when you are indoors?"

\begin{tabular}{|c|c|c|}
\hline \multicolumn{2}{|c|}{ If you are directly affected by the earthquake: What actions would you take when you are indoors? } \\
\hline & Control & Experimental \\
\hline Go under furniture/door frame & $51.72 \%$ & $52.78 \%$ \\
\hline Go to safe place & $13.79 \%$ & $16.67 \%$ \\
\hline Crouch & $6.90 \%$ & $2.78 \%$ \\
\hline Switch off gas/electricity & $3.45 \%$ & $0.00 \%$ \\
\hline
\end{tabular}


Table 7. Responses to question on "If you are directly affected by the earthquake: What actions would you take when you are outdoors?"

\begin{tabular}{|c|c|c|}
\hline \multicolumn{2}{|c|}{ If you are directly affected by the earthquake: What actions would you take when you are outdoors? } \\
\hline & Control & Experimental \\
\hline Go to open space/ away from buildings & $72.41 \%$ & $58.33 \%$ \\
\hline Seek family & $0.00 \%$ & $2.78 \%$ \\
\hline Get in vehicle & $0.00 \%$ & $2.78 \%$ \\
\hline
\end{tabular}

their answers. In other words, participants had high levels of awareness with respect to these two types of emergency situations.

The results, however, for the case where the emergency finds the participants inside a vehicle are significantly different. The majority of the control group (27.59\%) stated that they would leave the car, an action that is not recommended in the event of an earthquake. The answers from the experimental group almost exclude the option of leaving the car (2.78\%) and the majority preferred to stay in the car (38.39\%) which indicates that they have benefitted from the POP-ALERT dashboard.

The answers illustrated in Table 9 also reveal that using the dashboard has improved the awareness and preparedness of participants. The difference in the results is not particularly significant when looking at the most popular answers: water, canned food, flashlight and radio are items preferred by both groups. However, a high proportion of the experimental group's members have also selected the remaining items, while the control groups have practically ignored them. For example, toiletries, mobile phone, clothes and cash are examples of important items mostly ignored by the control group.

Finally, in the question regarding sources of information the results shown in Table 10 are mostly similar between the two groups. Both groups have identified TV and radio as primary sources of information, which is in accordance with the recommended course of action. We should note that a small proportion of participants have specifically identified the dashboard and emergency action cards included therein as a source of information, which is particularly encouraging since the existence of these sources was only recently revealed to the users. Finally, the majority of the experimental group have not included emergency services in their answers, which is also the recommended course of action since this would unnecessarily increase the workload of the respective call emergency communication centres dealing with urgent post-disaster incidents.

\section{Comparison with Preparedness Survey Results}

It is worth comparing the Lisbon trial results with an on-line emergency preparedness survey circulated among EU citizens in which over 1600 people across the EU participated (Filippoupolitis et al, 2015).

Table 11 illustrates the answer to a question related to reasons behind delaying the evacuation in an emergency situation. As we can observe, a high number of participants (32.7\%) stated that they would delay evacuating in order to care for their pets. Going back to Table 4, we can confirm that the majority of the control group $(51.72 \%)$ opted to take their pets with them during the evolving earthquake disaster. This confirms the fact that the answers coming from sample of population used in our field trial is in accordance with the results coming from the bigger sample that participated in the earlier survey.

Another comparison we can draw between the two population samples is related to the supplies and items they have allocated for use in the case of a disaster. Table 12 illustrates the results of the EU survey. We can observe that there is a similarity between the two samples, specifically with respect to the most popular items. For example, both the participants of the EU survey and of the trial have selected water, food, flashlight and radio as the most popular items to put in their emergency kit. In terms of the least popular items, there are minor variations between the two groups. However, items such as clothing and fire blankets are among the least popular choices for both the EU and the Lisbon 
Table 8. Responses to question on "If you are directly affected by the earthquake: What actions would you take when you are in a vehicle?"

If you are directly affected by the earthquake: What actions would you take when you are in a vehicle?

\begin{tabular}{|c|c|c|}
\hline & Control & Experimental \\
\hline Stay inside & $17.24 \%$ & $38.89 \%$ \\
\hline Stop car & $20.69 \%$ & $27.78 \%$ \\
\hline Drive to open area & $24.14 \%$ & $27.78 \%$ \\
\hline Leave car & $27.59 \%$ & $2.78 \%$ \\
\hline
\end{tabular}

Table 9. Responses to question on "List the items you would expect to find in your emergency kit/bag"

\begin{tabular}{|c|c|c|}
\hline \multicolumn{3}{|c|}{ List the items you would expect to find in your emergency kit/bag } \\
\hline & Control & Experimental \\
\hline Water & $51.72 \%$ & $61.11 \%$ \\
\hline Canned food & $51.72 \%$ & $55.56 \%$ \\
\hline Flashlight & $44.83 \%$ & $47.22 \%$ \\
\hline Radio & $41.38 \%$ & $47.22 \%$ \\
\hline First Aid Kit & $27.59 \%$ & $44.44 \%$ \\
\hline Batteries & $31.03 \%$ & $41.67 \%$ \\
\hline Medicine & $20.69 \%$ & $41.67 \%$ \\
\hline Knife & $10.34 \%$ & $27.78 \%$ \\
\hline Blanket & $10.34 \%$ & $25.00 \%$ \\
\hline Documents & $0.00 \%$ & $25.00 \%$ \\
\hline Mobile Phone & $0.00 \%$ & $22.22 \%$ \\
\hline Cash & $3.45 \%$ & $19.44 \%$ \\
\hline Clothes & $3.45 \%$ & $19.44 \%$ \\
\hline Toiletries & $0.00 \%$ & $19.44 \%$ \\
\hline Bandages & $13.79 \%$ & $0.00 \%$ \\
\hline Fire Extinguisher & $6.90 \%$ & $5.56 \%$ \\
\hline Matches/Lighter & $6.90 \%$ & $2.78 \%$ \\
\hline Charger & $0.00 \%$ & $2.78 \%$ \\
\hline
\end{tabular}


Table 10. Responses to question on "If you are unsure of what actions should be taken, where would you find this information?"

\begin{tabular}{|c|c|c|}
\hline \multicolumn{3}{|c|}{ If you are unsure of what actions should be taken, where would you find this information? } \\
\hline & Control & Experimental \\
\hline Radio & $41.38 \%$ & $47.22 \%$ \\
\hline Internet & $24.14 \%$ & $22.22 \%$ \\
\hline TV & $24.14 \%$ & $25.00 \%$ \\
\hline Civil protection & $24.14 \%$ & $5.56 \%$ \\
\hline Call 112 & $3.45 \%$ & $19.44 \%$ \\
\hline Fire service & $10.34 \%$ & $0.00 \%$ \\
\hline Authorities & $10.34 \%$ & $2.78 \%$ \\
\hline Police & $3.45 \%$ & $5.56 \%$ \\
\hline Smartphone & $17.24 \%$ & $2.78 \%$ \\
\hline Social Media & $10.34 \%$ & $2.78 \%$ \\
\hline First responders & $10.34 \%$ & $2.78 \%$ \\
\hline Emergency Contacts & $0.00 \%$ & $5.56 \%$ \\
\hline Discussing with others & $3.45 \%$ & $2.78 \%$ \\
\hline POP-ALERT platform & $0.00 \%$ & $2.78 \%$ \\
\hline Don't know & $0.00 \%$ & $2.78 \%$ \\
\hline Emergency Action cards & $0.00 \%$ & $2.78 \%$ \\
\hline Relatives & $0.00 \%$ & $2.78 \%$ \\
\hline
\end{tabular}

Table 11. Responses to the EU survey question on "Would you consider delaying evacuating in an emergency situation for any of the following reasons?"

\begin{tabular}{|c|c|}
\hline Would you consider delaying evacuating in an emergency situation for any of the following reasons? \\
\hline Evacuate my pet(s) & $32.7 \%$ \\
\hline Gather my personal belongings & $33.7 \%$ \\
\hline Gain clarity in the unfolding event & $48.6 \%$ \\
\hline Wait for directions from emergency management agencies & $40.2 \%$ \\
\hline Personal mobility issues & $5.9 \%$ \\
\hline Care for relative & $45.7 \%$ \\
\hline I would not delay evacuating & $17.3 \%$ \\
\hline I would not evacuate & $1.2 \%$ \\
\hline Other & $2.9 \%$ \\
\hline
\end{tabular}


participants. These observations also reinforce the fact that the characteristics of our trials sample are in accordance with those observed in the EU survey participants.

\section{CONCLUSION}

The work described in this paper is based on a number of years of research both into distributed eLearning and crisis management and response, and as a result offers a research-informed practical contribution to the existing provision of services for population awareness, training and preparation. It still remains the case that much of the training on offer in crisis response is either paper-based, or expensive field events or simulations, primarily targeted at first responders in the emergency services. The Pandora project sought to provide a rich multimedia, immersive training environment for strategic crisis managers (Gold Commanders) that could offer relatively low cost, repeatable and self-configured training events. The Pandora ${ }^{+}$environment offers a production-level system to provide such training across a wide variety of domains, on a commercial basis. Linking this in to the other research work described in the paper, a unique, scalable model for the design of learning materials to support training in crisis preparation and response has been demonstrated. Research work on eLearning, particularly focused on the use of MOOCs, highlights a number of issues of relevance to offering a massively open and distributed training course on crisis response and preparation. In particular, building a bitesize model of delivery, to reflect user preference for quick and short engagement, accepting user models of engagement whenever they wish and for as long as they wish, and rewarding engagement rather than completion. In terms of educating the population, particular encouragement can be drawn from a willingness expressed by the population to prepare, but a lack of knowledge of how to, or where to find the information, is holding back the preparedness of citizens.

On the basis of this background research, the Pandora ${ }^{+}$environment has been revised to offer support for both the existing trainer-led exercise model for which it was originally designed, and for a widely distributed, web service model allowing relatively random trainee (members of the public) engagement. These trials have provided valuable feedback on both the POP-ALERT dashboard and use of the Pandora ${ }^{+}$system, both of which were extremely positive, and now provides the green light to provide training on crisis management to the general public on a large scale, with the potential to have a significant impact on the preparedness of the EU population for a crisis. The authors believe that, not only have the enhancements to the Pandora ${ }^{+}$system demonstrated the capacity to provide a distributed, online, immersive, multimedia, engaging environment designed for mass education of the public to support them in developing their crisis preparation and response skills on the scale of a MOOC, but that the results of the trials and the survey have potential to inform current thinking on crisis preparedness education for the population. Future enhancements to Pandora ${ }^{+}$include the release of more training scenarios, further development of the behavioural framework to automate the stress management of a trainee in the absence of a trainer, and to provide intelligent agents as scenario avatars to augment the immersive characteristics of a scenario.

\section{ACKNOWLEDGMENT}

The authors would wish to acknowledge the support of the European Commission for funding the following three projects.

1. Pandora project under the IST \& Security Call of the $7^{\text {th }}$ Framework - FP7-ICT-SEC-2007-1, Grant Agreement No. 225387

2. POP-ALERT project under the security theme of the $7^{\text {th }}$ Framework, call SEC-2013.4.1-5 grant agreement 608030.

3. dCCD-FLITE project under the Erasmus Lifelong Learning programme, agreement number 2013-4354/ 001-001, project number 539249-LLP-1-2013-1-SE-ERASMUS-EKA.

We would also wish to acknowledge and thank our partners in all three projects for their contributions to this work. 
Table 12. Responses to the EU survey question on "Which of the following supplies do you have in your home in case of a disaster?"

\begin{tabular}{|l|l|}
\hline \multicolumn{2}{|c|}{ Which of the following supplies do you have in your home in case of a disaster? } \\
\hline Water container & $47.8 \%$ \\
\hline Non-perishable food & $64.6 \%$ \\
\hline Flashlight & $81.1 \%$ \\
\hline Battery operated radio & $32.4 \%$ \\
\hline Batteries & $74.3 \%$ \\
\hline First aid kit & $70.4 \%$ \\
\hline Medication & $71.2 \%$ \\
\hline Photocopies of ID & $36.5 \%$ \\
\hline Battery operated mobile phone & $54.2 \%$ \\
\hline Mobile phone charger & $83.3 \%$ \\
\hline Candles & $79.1 \%$ \\
\hline Whistle & $31.1 \%$ \\
\hline Matches / Lighter & $84.7 \%$ \\
\hline Fire blanket & $21.7 \%$ \\
\hline Protective clothing & $36.7 \%$ \\
\hline None of the above & $1.7 \%$ \\
\hline Other & $2.9 \%$ \\
\hline
\end{tabular}




\section{REFERENCES}

Bacon, L., MacKinnon, L., Anderson, M., Hansson, B., Fox, A., Cecowski, M., .. Stamatis, D. (2015). Addressing retention and completion in MOOCs - a student-centric design approach. In E-LEARN 2015 - World Conference on E-Learning, Kona, Hawaii, October 19-22.

Bacon, L., MacKinnon, L., Cesta, A., \& Cortellessa, G. (2012). Developing a Smart Environment for Crisis Management Training. Journal of Ambient Intelligence and Humanized Computing, 3(2). doi:. Retrieved from http://www.springerlink.com/content/r586h5354923/?MUD=MP10.1007/s12652-012-0124-0

Bacon, L., MacKinnon, L., \& Kananda, D. (2015). Real-time Decision Support in Online Training Environments. In Proceedings of the XIII LACCEI Conference, Santa Domingo July 29-31. doi:10.18687/LACCEI2015.1.1.192

Bagrow, J., Wang, D., \& Barabási, A.-L. (2011). Collective response of the human populations to large scale emergencies. Journal Plos One, 6(3), e17680. Retrieved from http://www.plosone.org/article/ info\%3Adoi\%2F10.1371\%2Fjournal.pone.0017680\#pone-0017680-. doi:10.1371/journal.pone.0017680 PMID:21479206

Bernard, R. M., Rojo de Rubalcava, B., \& St-Pierre, D. (2000). Collaborative online distance learning: Issues for future practice and research. Distance Education, 21(2), 260-269. doi:10.1080/0158791000210205

Dow, K., \& Cutter, S. L. (1998). Crying wolf: Repeat responses to evacuation orders. Coastal Management, 26(4), 237-252. doi:10.1080/08920759809362356

Dow, K., \& Cutter, S. L. (2000). Public orders and personal opinions: Household strategies for hurricane risk assessment. Environmental Hazards, 2(4), 143-155. doi:10.1016/S1464-2867(01)00014-6

Ellis, A. (2001). Student-centred collaborative learning via face-to-face and asynchronous online communication: What's the difference. In Proceedings 18th ASCILITE Conference Melbourne.

Filippoupolitis, A., MacKinnon, L., \& Bacon, L. (2015). A Survey on Emergency Preparedness of EU Citizens. In Proceedings of the ISCRAM 2015 Conference, May 24-27.

Klaiman, T., Knorr, D., Fitzgerald, S., DeMara, P., Thomas, C., Heake, G., \& Hausman, A. (2010). Locating and communicating with at-risk populations about emergency preparedness: The vulnerable populations outreach model. Disaster Medicine and Public Health Preparedness, 4(3), 246-251. doi:10.1001/dmp.2010.25 PMID:21149222

Kop, R., Fournier, H., \& Sui Fai Mak, J. (2011). A pedagogy of abundance or a pedagogy to support human beings? Participant support on massive open online courses. International Journal of Research in Open and Distance Learning, 12(7). Retrieved from http://www.irrodl.org/index.php/irrodl/article/view/1041/2025

Lalo, A. (2000). Alerting the population in emergency plans: Examples of local public policy in Provence. Journal of Hazardous Materials, 78(1-3), 281-301. doi:10.1016/S0304-3894(00)00227-2 PMID:10978571

Legates, D., \& Biddle, M. (1999). Warning response and risk behaviour in the Oak Grove - Birmingham, Alabama Tornado of April 8, 1998. Boulder, CO: Natural Hazards Research and Applications Information Centre, Institute of Behavioural Science, University of Colorado.

Leonard, G. S., Johnston, D. M., Paton, D., Christianson, A., Becker, J., \& Keys, H. (2008). Developing effective warning systems: Ongoing research at Ruapehu volcano, New Zealand. Journal of Volcanology and Geothermal Research, 172(3), 199-215. doi:10.1016/j.jvolgeores.2007.12.008

Lindell, M. K., \& Perry, R. W. (2004). Communicating Environmental Risk in Multiethnic Communities. Thousand Oaks, CA: Sage Publications.

MacKinnon, L., Bacon, E., Cortellessa, G., \& Cesta, A. (2013). Using Emotional Intelligence in Training Crisis Managers: The Pandora Approach. The International Journal of Distance Education Technologies, 11(2), 66-95. Retrieved from http://www.igi-global.com/article/using-emotional-intelligence-training-crisis/77841

Mileti, D. S., \& Peek, L. (2000). The social psychology of public response to warnings of a nuclear power plant accident. Journal of Hazardous Materials, 75(2-3), 181-194. doi:10.1016/S0304-3894(00)00179-5 PMID:10838242 
Paton, D. (2006). Risk Communication project (C4) Warning systems: Issues and consideration for warning the public (Draft report). Retrieved from http://www.bushfirecrc.com/managed/resource/paton-bushfirewarnings_wcover_1.pdf

Perry, R. W., Lindell, M. K., \& Greene, M. R. (1982). Crisis communications: Ethnic differentials in interpreting and acting on disaster warnings. Social Behaviour and Personality: An International Journal, 10(1), 97-104. doi:10.2224/sbp.1982.10.1.97

POP-ALERT. (2015). (Project website). Retrieved from http://www.pop-alert.eu/

Quarantelli, E. (1994). Perceptions and reactions to emergency warnings of sudden hazards. Ekistics, 309, $511-515$.

Salas, E., Driskell, J., \& Hughs, S. (1996). The study of stress and human performance. In J. Driskell \& E. Salas (Eds.), Stress and Human Performance. New Jersey: Lawrence Erlbaum Associates.

Seydlitz, R., Spencer, J. W., \& Lundskow, G. (1994). Media Presentations of a Hazard Event and the Public's Response: An Empirical Examination. International Journal of Mass Emergencies and Disasters, 12, 279-301.

Vihalemm, T., Kiisel, M., \& Harro-Loit, H. (2012). Citizens' response patterns to warning messages. Journal of Contingencies and Crisis Management, 20(1), 13-25. doi:10.1111/j.1468-5973.2011.00655.x 
Liz Bacon BSc, PhD, CEng, CSci, CITP, FBCS, PFHEA, MACM is a Deputy Pro-Vice-Chancellor at the University of Greenwich in London, with a University wide remit leading the development of technology enhanced learning. She was President of BCS, The Chartered Institute for IT, in the year 14-15 and is a past Chair of the BCS Academy of Computing, and the CPHC (Council of Professors and Heads of Computing) national committee. Liz is a Professor of Software Engineering with over a hundred publications and a Co-Director of the eCentre research group. She has been involved in several EU research projects, including being Principal Investigator and Project Coordinator for two EU FP7 projects in the recent past. She is an experienced systems designer and developer and her research interests include computing policy, smart systems, security, technology enhanced learning and crisis management.

Lachlan MacKinnon BSc, PhD, FBCS, CITP, CEng, MIEEE, MACM, MAACE is Professor of Computing Science (Strategic Development), and Head of the Department of Computing \& Information Systems, in the Faculty of Architecture, Computing \& Humanities, University of Greenwich, U.K. He is also Visiting Professor of Computer Science at RMIT University, Melbourne, Australia, and Visiting Professor of Games \& Multimedia Technology at University College of SouthEast Norway, Kongsberg, Norway. Professor MacKinnon is a former Chair of the UK national Committee of the Council of Professors and Heads of Computing (CPHC), and Chair of the Education Committee of the BCS Academy of Computing. He is Chair of the Executive Committee of the British National Conference on Databases, and a member of the UK National Committee of the British Human Computer Interaction Group. His research interests are in computing policy, information and knowledge engineering, smart systems, games and creative technologies, eHealth and eLearning, and cybersecurity.

Avgoustinos Filippoupolitis is a senior lecturer in Disruptive Technologies, carrying out research in distributed systems and machine learning with applications to the Internet of Things, Emergency Preparedness for large scale disasters and Cyber-profiling. Avgoustinos was awarded his PhD on emergency simulation and decision support algorithms for smart buildings from Imperial College. His work was competitively selected for demonstration in the Home Office INSTINCT programme, aiming at reducing the risk of terrorist attacks in crowded urban areas. He has collaborated with MBDA Systems under an EPSRC Knowledge Transfer Secondment for the exploitation of his research on discrete event simulation and modelling for urban security. He is currently an independent expert in the evaluation of Horizon 2020 proposals.

David Kananda has a BSc (Hons) in Computing from the University of Greenwich and has worked on the Pandora+ project as a software developer for over 4 years. His specialist areas of expertise are in web service development, and cloud deployment, using technologies such as Java, JavaScript, Bootstrap, Angular, Docker and AWS inter alia. He also has expertise in database design and development using MySQL, MongoDB and NoSQL, deployment tools and testing, and was the designer of the decision branching mechanism within the Pandora+ system. 